\title{
Study of the diffusion behavior of water vapor sorption in natural fiber composite: Plaster/ Rhecktophyllum camerunense
}

\begin{abstract}
The present work focuses on the study of water sorption phenomenon in natural fiber composite (NFC) plaster/Rhecktophyllum camerunense (RC). Indeed, the diffusive behavior of the composite was investigated. The NFC samples were submitted to hygro-thermal ageing in an environmental enclosure of $23 \%, 54 \%$ and $75 \%$ relative humidities at $23^{\circ} \mathrm{C}$. Periodic gravimetric measurements were achieved on the specimens in order to follow their kinetics adsorption. The results show that the kinetic adsorption is rapid at the first hours no matter the relative humidity and begin saturation after 28 hours. The maximum moisture content increases with the relative humidity. Predictive Fick's Law was used to modelling experimental data. The curves of all humidities don't obey to the Fick's model and the diffusion coefficients have been deduced. We observed that the diffusion coefficient increase with the relative humidity.
\end{abstract}

Keywords: NFC, diffusion, moisture, modelling, Fick's law
Volume 3 Issue I - 2019

\author{
Noutegomo Boris,' Betene Ebanda, ${ }^{2}$ \\ Atangana Ateba ${ }^{2}$ \\ 'Laboratory of Mechanical, University of Douala, Cameroun \\ ${ }^{2}$ Department of Mechanical Engineering, University of Douala, \\ Cameroun
}

Correspondence: Noutegomo Boris, Laboratory of

Mechanical, University of Douala, Cameroun,

Email borisnoutegomo@yahoo.fr

Received: January 21, 2019 | Published: January 28, 2019

\section{Introduction}

Moisture content in NFC significantly affects their physical and mechanical properties. Moisture transfer in these composites influences dimensional stability and durability. The absorbed moisture results in to the deterioration of mechanical properties since the water not only affects the unfilled matrices physically and/or chemically but also attacks the hydrophilic natural fiber as well as the fibermatrix interface. ${ }^{1}$ For their use as reinforcement, the hydrophilic nature of plant fibers has to be considered with carefulness for several reasons. First, during the life cycle of the material, water absorption could induce a volume change of the fibers inside the composite, leading to the development of internal stresses. On the other hand, during the polymerization process of the matrix above $100^{\circ} \mathrm{C}$, a vaporization of water trapped inside fibers could occur, leading to their shrinkage. These swelling and shrinkage of the fibers surrounded by the matrix generate internal stresses at the fiber/matrix interface and can eventually lead to the damage of the latter and to a significant degradation of the initial properties of the composite. The works of Rangaraj and Smith; ${ }^{2}$ Dhakal et al., ${ }^{3}$ Le Duigou et al., ${ }^{4} \mathrm{Hu}$ et al., ${ }^{5}$ Assarar et al., ${ }^{6}$ deal with water sorption of composites reinforced by bio-based fibers. For example, in their work on the water uptake of a flax fiber composite material Assarar et al., ${ }^{6}$ showed an increase of the water content absorbed, compared to a material consisting of the same matrix reinforced with glass fibers. Le Duigou et al. ${ }^{4}$ studied the behavior of a composite PLLA/flax in immersion in sea water. The weight gain curves showed the influence of the cellulose fibers. The saturated moisture contents of the specimens were around $5.6 \%$. Secondly, Le Duigou et al. ${ }^{4}$ showed a loss of the mechanical properties of the composite and an irreversible damage of the fiber/matrix interface during wet ageing. As mentioned before, this interface is a critical area considering the moisture absorption.

The water diffusing in the composite material creates hydrogen bonds with the fibers, which can lead to the reduction of the interactions between the fibers and the matrix. To prevent this phenomenon, fiber surface properties could be modified by physical treatments (cold plasma treatment and corona treatment) and chemical treatments (maleic anhydride, organosilanes, isocyanates, sodium hydroxide, permanganate, alkaly and peroxide) in order to promote adhesion., ${ }^{1,7}$ A lot of investigations have been done on the absorption of NFC immersed in water but few studies have been done on their adsorption moisture exposed to ambient relative humidity. ${ }^{8}$ It is the topic of the present work. By doing gravimetric measurements and using predictive model we want to understand the diffusion moisture behavior of NFC.

RC plant as presented on Figure 1 is the camerunense type of the Rhectophyllum species, a member of Araceae family. It was identified for the first time in 1981 by the botanist Colette Ntépé-Nyamè in the forests of Southern Cameroon, Nigeria and Gabon. ${ }^{9}$ It is a plant erected on stilt roots being able to reach $50 \mathrm{~cm}$ in height, with a short, thick stem, then crawling on an emitted stolon at its top and being able to carry leaves. It has two kinds of air roots: long vertical roots reaching the ground, from 1.5 to $4 \mathrm{~cm}$ wide, pubescent, non- warted and short horizontal cramp roots, also flattened and pubescent. A thinner stolon allows the progression of the plant either on the ground or on a tree support. It rises to a height of around $100 \mathrm{~m}$, The RC fibers are extracted from the long air roots and are traditionally used to make ropes, baskets and fishing nets. It is a fiber recently studied and the first works carried out show that it has good mechanical properties: The density of the fiber was found to be one of the lowest up to now studied with a porosity which is about 28 to $36 \%$ according to the size of the fiber. Chemical analysis has revealed that cellulose content is $68.2 \%$. Inspire of its average Young modulus nearly the same as for sisal fiber; it has a good strength and highest elongation at break up to $50 \% .^{10}$ The high micro fibril angle of $40^{\circ}$ enables him to have a good shock behavior. It is an élasto-ductile fiber but adheres less on the plaster when it is used as reinforcement, but procure its ductile character to him. It hydrophilic character brings to the plaster more moisture than when it is not reinforced. ${ }^{11}$ Modelling the moisture sorption isotherms of the (RC) fiber at $23^{\circ} \mathrm{Cby}$ using the $\mathrm{BET}, \mathrm{GAB}$ and DLP models have been studied and they presented the sigmoid shape of type II with excellent adjustments. ${ }^{12}$ The diffusion behavior of water vapor sorption in this fiber has been also studied..$^{13}$ The plaster, manufactured starting from gypsum has many uses as fabrication of 
the distribution partitions or housing separation. They are also use as ceilings or doubling of walls. They are used in accoustics isolation, thermal and hygroscopic regulation of enclosures. The plaster is much used in interior decoration and in hospital for fractures because of its capacity to be moulded on all the forms. Its great brittleness is at the origin of research works in whole the world for its reinforcement. Today, glass and sisal fibers are the reinforcements most used. Reinforcement by vegetable fibers is increasingly required. Many works show that the reinforcement of the plaster by the natural fibers increases his mechanical properties and his capacity in moisture absorption. ${ }^{11,14-16}$

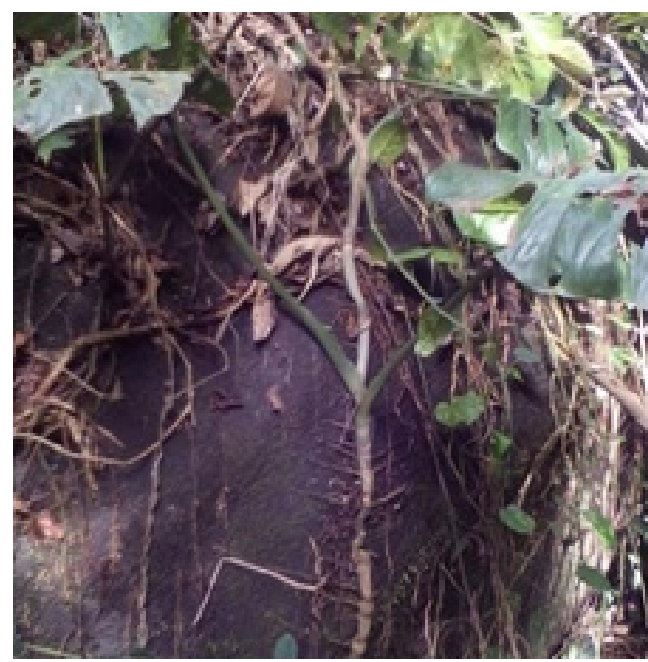

Figure I RC plant. ${ }^{12}$

Hydrophilic behavior of natural fibers and their relation with the presence of free hydroxyl group in its structure was related by many practical ${ }^{16,17}$ and modelling studies. These authors employed physical models applied to polymers to describe the diffusion behavior of water in natural fibers, such as Fick's law, ${ }^{18}$ the Langmuir theory and dual- stage Fick's law. ${ }^{19}$

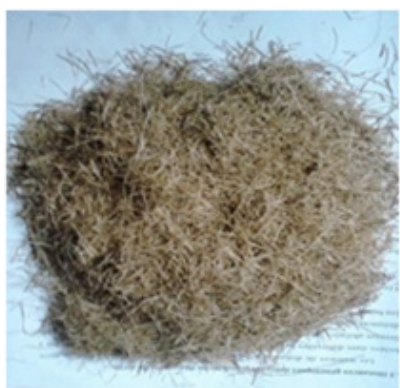

A. RC fibers

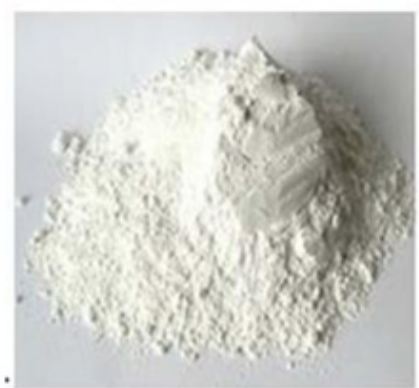

B. plaster powders $\beta$

\section{Material and methods}

\section{Material}

The untreated RC fibers were used in this study. They were extracted from the roots of plants harvested in the wet equatorial forests of the center Cameroon. The roots used were fresh. We also use the thermostatic oven of Memmert mark to dry samples of NFC. A balance PMI 400 mark with a precision of $0.001 \mathrm{~g}$ were used to carry out weighings. A desiccator containing silica crystals to maintain samples at dry state. Three chemical salts were used for preparing saturated aqueous solutions to create relative humidity in a small enclosure as mentioned in Table 1 . We also used a wood mould with internal dimensions of $115 \times 20 \times 20 \mathrm{~mm}^{3}$ for the production of samples. The conditioning small enclosure was made up with the plastic bottles.

\section{Methods}

The extraction of fibers was made by our care according to an unstandardized method used at the reference. ${ }^{10}$ The processing of samples consists in mixing water and plaster until obtaining a paste then versed it in the mould. Thereafter introduce fibers into the paste and mixing. The processing period was $3 \mathrm{~min}$. The ratio water/ composite in term of mass is 1 and the ratio fibers/matrix is $02 \%$. Those samples are presented on Figure $2 \mathrm{c}$ above.

\section{The adsorption test}

The adsorption moisture test procedure is described by NF EN ISO 483: 2006-01 standard. It was carried out in science du sol laboratory of the Faculty of Agronomic and Agricultural Sciences (FASA) of Dschang University. The saturated salt solutions were prepared with distilled water 24 hours before the beginning of the test at $23 \pm 1^{\circ} \mathrm{C}$. The NFC were dried to $105^{\circ} \mathrm{C}$ for 48 hours and introduced into a desiccator to avoid reabsorption of ambient moisture. For each environmental condition three specimens were introduced in small enclosure as presented in Figure 3. Periodic gravimetric measurements were achieved until the saturation period was reached in order to observe the kinetic adsorption of moisture on the specimens.
Figure 2 Materials used.
The mass of water gain $\mathrm{X}$ is calculated for each relative humidity according to the following expression:

$$
X(\%)=\frac{M_{t}-M_{o}}{M_{o}} \times 100 \quad(1)
$$

Where $M_{t}$ is the mass of sample in wet state, $M_{o}$ the mass of anhydrous sample. This equation is used to study the kinetic absorption of moisture in materials by observing the curve of water content as a function of time. There are three major mechanisms of moisture

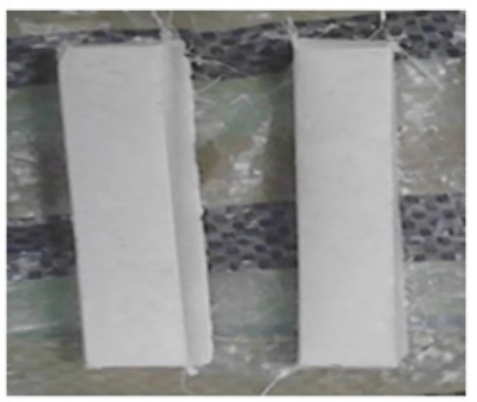

\section{NFC specimen}

absorption in composite. First diffusion of water molecules inside the micro gaps between matrix chains; second the capillary transport of water molecules into the gaps and flaws at the interface between fibers and the matrix due to the incomplete wettability and finally the third mechanism is the transport of water molecules by micro cracks in the matrix, formed during the compounding process. These three cases of diffusion can be distinguished theoretically by the shape of the sorption curve representedby: 


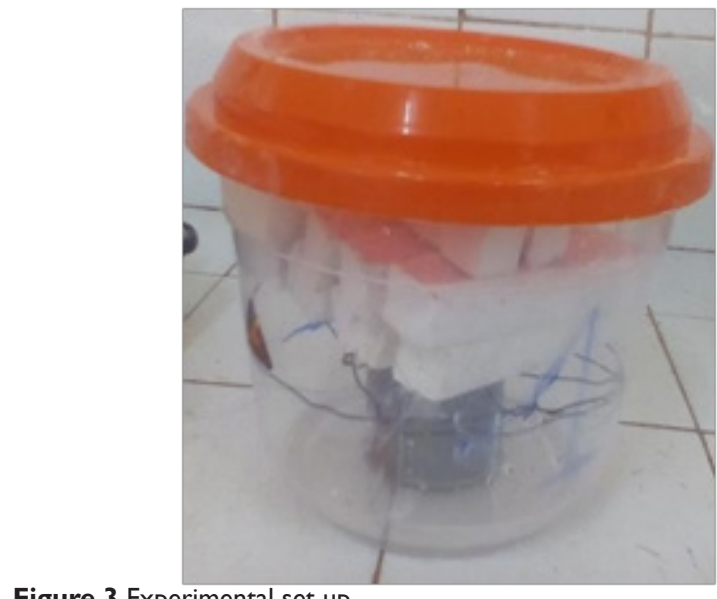

Figure 3 Experimental set up.

Table I Salt solutions used and their relative humidity $(\mathrm{RH})$ at saturation ${ }^{12}$

\begin{tabular}{llll}
\hline Saturated Salt solution & $\begin{array}{l}\text { Solubility } \\
(\mathbf{g} / \mathbf{l})\end{array}$ & $\begin{array}{l}\text { Quantity for } \mathbf{2 0} \mathbf{~ m l} \\
\text { of water }(\mathbf{g})\end{array}$ & $\begin{array}{l}\mathbf{R H}(\%) \text { at } \\
\mathbf{2 3} \mathbf{C}\end{array}$ \\
\hline $\begin{array}{l}\text { Potassium acetate } \\
\text { Magnesium nitrate }\end{array}$ & 2000 & 42 & 23 \\
$\begin{array}{l}\text { hexahydrated } \\
\text { Sodium chloride }\end{array}$ & 1250 & 27.5 & 54 \\
\hline & 357 & 8 & 75 \\
\hline & $\frac{M_{t}}{M_{n}}=k t^{n}$ & and $\log \frac{M_{t}}{M_{n}}=\log (k)+n \log (t)(2)$
\end{tabular}

Where, $M_{t}, M_{n}, k$, and $\mathrm{n}$ are the water absorption at time $\mathrm{t}$, the water absorption at the saturation point, and constants, respectively. The coefficients ( $\mathrm{n}$ and $\mathrm{k}$ ) are calculated from slope and the value of $\mathrm{n}$ is different for each case intercept of $\log$ plot of $\frac{M_{t}}{M_{n}}$ versus time which can draw from experimental data. The value of $n$ indicate the type of the diffusion mechanism. When $n=0.5$ following Fickian behavior. For non-Fickian diffusion, the value of $\mathrm{n}$ is between 0.5 and 1 . When the value of $\mathrm{n}$ is less than 0.5 , anomalous diffusion takes place. The value of $\mathrm{k}$ indicates the interaction between water and the composite. The experimental data are fitted with the traditional Fickian diffusion model. ${ }^{16}$ This is the most common model used for the diffusion of humidity in materials. The model is consistent on the so-called free volume theory. ${ }^{18}$ Considering a parallelepiped with rectangular section in which diffusion is everywhere radial (one dimensional case), the moisture concentration $\mathrm{C}$ is then a function of length $\mathrm{x}$ and time $\mathrm{t}$, and the diffusion equation is written as follow: ${ }^{19}$

$$
\frac{\partial c}{\partial t}=D\left(\frac{1}{x} \frac{\partial c}{\partial t}+\frac{\partial^{2} c}{\partial x^{2}}\right)
$$

Where $\mathrm{D}$ is the diffusion coefficient

Indeed, the integration of the analytical solution of Eq. (3), over the parallelepiped length $\mathrm{x}$ yields the following expression of moisture uptake:

$$
\frac{M_{t}}{M_{\infty}}=1-\sum_{n=1}^{\infty} \frac{4}{a^{2} \alpha_{n}^{2}} \exp \left(-D \alpha_{n}^{2} t\right) \text { (4) }
$$

Where $J_{0}(x)$ is the first kind Bessel function of order zero. Indeed the values of $\alpha n$ are the roots of the first species of Bessel's function at order 0 . By simplify the equation (4) the diffusion coefficient D can be deduced at the initial linear stage of Fick's curve by the Following equation (5):

$$
D=\pi\left(\frac{h}{4 M_{n}}\right)^{2}\left(\frac{M_{2}-M_{1}}{\sqrt{t_{2}}-\sqrt{t_{1}}}\right)^{2}\left(\mathrm{~mm}^{2} / \mathrm{s}\right)
$$

Where $\mathrm{h}$ is the thickness of composite $(\mathrm{mm})$

\section{$M_{n}$ Maximum moisture content $(\mathrm{g} / \mathrm{g})$}

$M_{2}, M_{1}$ are the moisture contents corresponding to times $\mathrm{t}_{2}, \mathrm{t}_{1}$ of the initial linear phase of the Fick curve.

The Fick curve expresses the moisture content versus the square root of time. The first phase of that curve is linear and the second phase is curvilinear. The diffusion coefficient $\mathrm{D}$ expresses the speed to which the process of the diffusion takes place. It is the diffusion speed of substance per unit of section divided by the gradient of concentration in that section. The statistical analysis of experimental data have been done in the Matlab 2014a software environment which enabled drawing experimental curves. The Fick model will fit well the experimental data if it has an average correlation coefficient near to the unit, the square root of mean error average near zero, and the sum of square error average near zero.

These two last statistical parameters are defined by the following equations (6) and (7)

$$
\begin{aligned}
R M S E & =\sqrt{\frac{\sum_{i=1}^{n}\left(m_{c i}-m_{e i}\right)^{2}}{n}}(6) \\
S S E & =\sum_{i=1}^{n}\left(m_{C i}-m_{e i}\right)^{2}(7)
\end{aligned}
$$

where $m_{c i}, m_{e i}$, and $n$ are respectively the theoretical mass, the predicted mass, and the number of observation respectively.

\section{Result and discussions}

Figure 4 presents the kinetic absorption of NFC at the relative humidities of 23,54 and $75 \%$ at $23^{\circ} \mathrm{C}$. The moisture content increases with the relative humidity. Those curves have the same look for all the relatives humidities. They rather quickly absorb moisture in the first hours and start saturation at 28 hours. As observed in literature, naturals fibres need only 5 to 12 hours to reach saturation ${ }^{8,12,18}$ It is thus obvious that the plaster, as others matrix reduce the kinetic adsorption of natural fibers inside the composite. Similar examples have been observed in the literature: plaster/natural fibers $\left(98 \mathrm{RH}, 23^{\circ} \mathrm{C}\right),{ }^{11}$ unsaturated polyester/flax $(33,50$ and $75 \mathrm{RH}) .{ }^{8}$ Table 2 below presents the difference between moisture content of the unreinforced plaster found in the literature and the composite plaster/RC carried out in our experiments. While comparing these two types of materials we realize that their moisture content increase with the relative humidity. However, it is higher for the composite. The weight gain shows the influence of the cellulose fibers in the composite. The water diffusing in the composite material creates hydrogen bonds with the fibers, which can lead to the reduction of the interactions between the fibers and the matrix. The capillarity mechanism could involve the flow of water molecules along fiber/matrix interfaces as well as a process of diffusion through the bulk matrix. This could result in a debonding of the fiber and the matrix. This water is bound to the network by hydrogen bonds breaking the existing bonds between the hydroxyl groups of the matrix chain. Table 3 show $\mathrm{n}$ and $\mathrm{k}$ coefficients. The value of $\mathrm{n}$ are more than 0.5 . This enable to conclude that the diffusion is non-fickian.

\section{Fick modeling}

Modeling by the Fick law consisted of adjusting the experimental data of water content with respect to the square root of time by using Fick's equations as presented at equations 4 . We used the nonlinear regression of the Marquardt-Levenberg algorithm with the support of Curve Fitting Toolbox of MATLAB software. Figures 5-7 present 
the results. Observing Figures 5-7 we have an initial phase which is linear on a very short time and for a moisture content going around $60 \%$ of the maximum moisture content. The second phase which is nonlinear and extends over a long period is concave to horizontal axis. The values of $n$ which are over 0.5 according to Table 2 permit to conclude that the diffusion is non-fickian at all relative humidities. The diffusion coefficients are deduced by using equation (5) and the result are presented in Table 3. They also increase with relative humidity. After getting the diffusion coefficients, we evaluate his behavior with respect to the relative humidity as presented in Figure 8. It appears that the diffusion coefficient increases with the relative humidity. Good correlation between experimental and model was found as indicated by the values of correlation coefficients in Table 4. The values of calculated correlation coefficients for the water absorption curves of all relative humidities are higher than the critical value of the correlation coefficient for a set of measured values at elected significance level $\mathrm{p}=0.05$.

Table 2 Difference between moisture content of the unreinforced plaster found in the literature and the composite plaster/RC carried out in experiments

\begin{tabular}{lll}
$\begin{array}{l}\text { Relatives } \\
\text { Humidities (\%) }\end{array}$ & $\begin{array}{l}\text { Moisture Content of } \\
\text { unreinforced plaster }(\%)^{12}\end{array}$ & $\begin{array}{l}\text { Moisture content of } \\
\text { composite Plaster/RC (\%) }\end{array}$ \\
\hline 23 & 0.06 & 4.07 \\
54 & 0.13 & 4.55 \\
75 & 0.30 & 7.642 \\
\hline
\end{tabular}

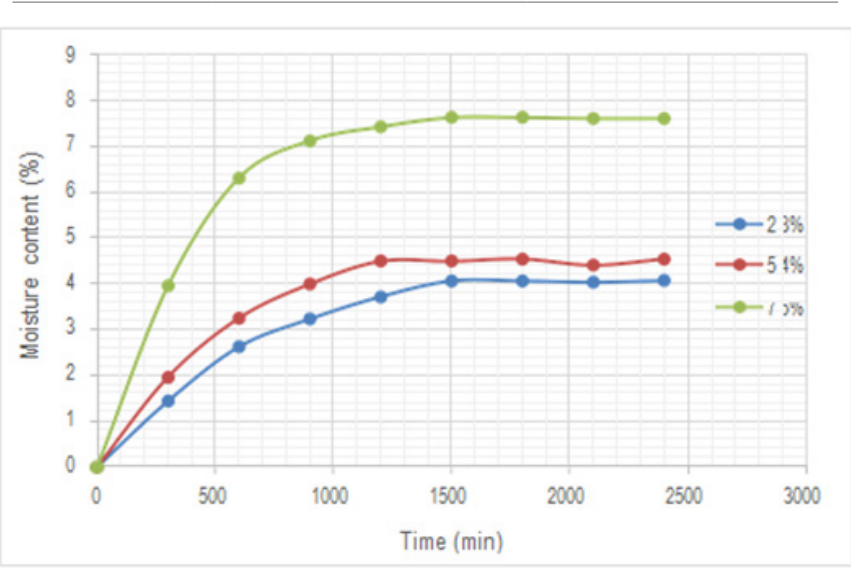

Figure 4 Kinetics adsorption of NFC at different relative humidities.

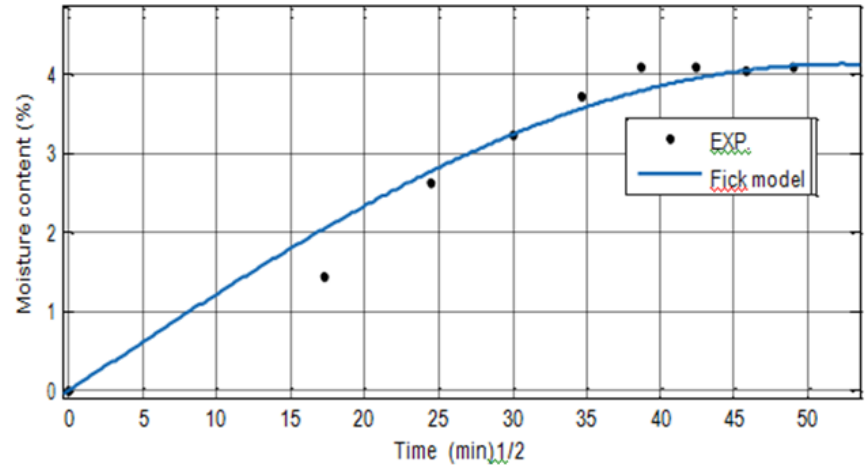

Figure 5 Experimental curve and Fick modeling for a relative humidity of $23 \%$.
Table $3 \mathrm{n}$ and $\mathrm{k}$ coefficients

\begin{tabular}{lll}
\hline Relatives Humidities (\%) & $\mathbf{n}$ & $\mathbf{K}(\mathbf{s})$ \\
\hline 23 & 0,687 & 0,117 \\
54 & 0,653 & 0.146 \\
75 & 0.705 & 0.250 \\
\hline
\end{tabular}

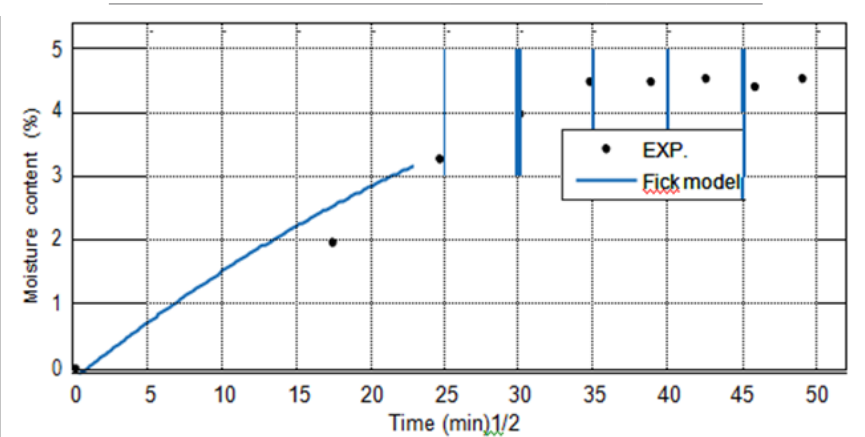

Figure 6 Experimental curve and Fick modeling for a relative humidity of 54\%.

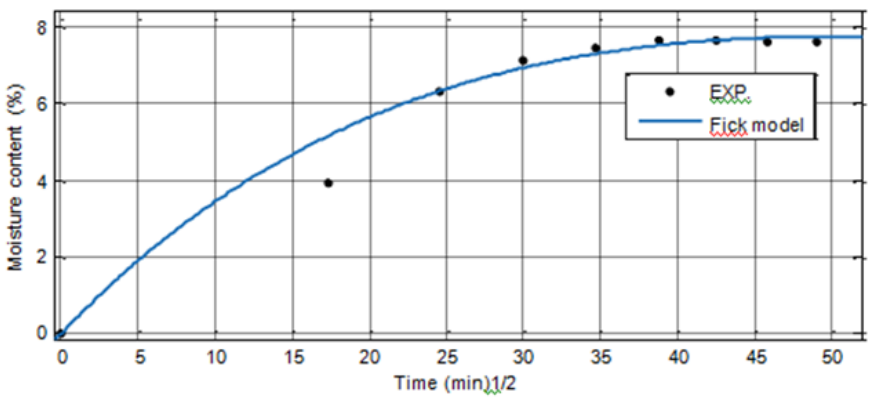

Figure 7 Experimental curve and Fick modeling for a relative humidity of $75 \%$.

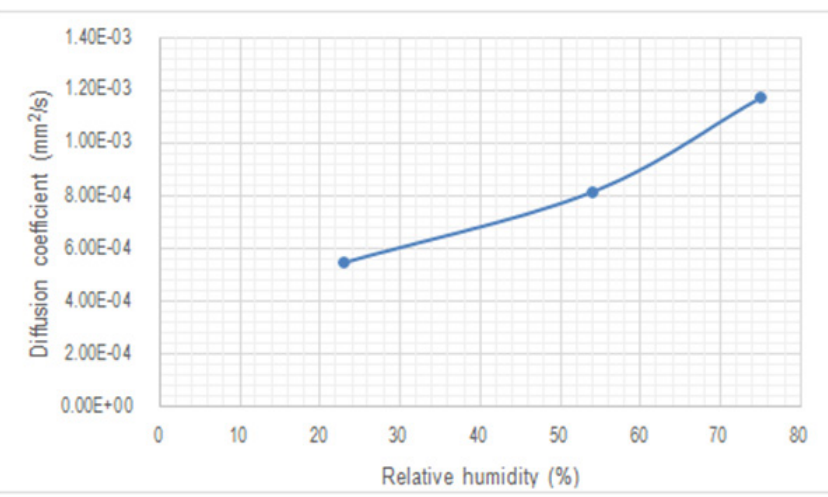

Figure 8 Evolution of diffusion coefficient with respect of relative humidity.

Table 4 Diffusion coefficient versus relative humidity

\begin{tabular}{lllll}
\hline $\begin{array}{l}\text { Relative } \\
\text { Humidities } \\
(\%)\end{array}$ & $\begin{array}{l}\text { Diffusion } \\
\text { Coefficients } \\
\mathbf{D}\left(\mathbf{m m}^{2} / \mathbf{s}\right)\end{array}$ & $\mathbf{R}^{2}$ & RMSE & SSE \\
\hline 23 & $5,46 \mathrm{e}-04$ & 0.9688 & 0.2945 & 0.5203 \\
54 & $8,14 \mathrm{e}-04$ & 0.9611 & 0.3113 & 0.5815 \\
75 & $11,7 \mathrm{e}-04$ & 0.9857 & 0.3929 & 0.772 \\
\hline
\end{tabular}




\section{Conclusion}

NFC have been manufacturing by mixing plaster and untreated $\mathrm{RC}$ fiber. The samples were submitted to hydrothermal ageing in conditioning small enclosure of $23,54,75 \% \mathrm{RH}$ at $23^{\circ} \mathrm{C}$. Periodic gravimetric measurements were achieved on the specimens in order to follow their kinetics adsorption. It shows that moisture absorbed increases with relative humidity. Compare to the unreinforced plaster, cellulosic fibers increase more than the water content of the plaster. This would result in the fact that the capillarity mechanism could involve the flow of water molecules along fiber/matrix interfaces as well as a process of diffusion through the bulk matrix. This could result in a debonding of the fiber and the matrix. This water is bound to the network by hydrogen bonds breaking the existing bonds between the hydroxyl groups of the matrix chain. Predictive Fick's Law has been used to modelling experimental data. The curves of all humidities don't obey to the Fick's model and the diffusion coefficients have been deduced. We observed that the diffusion coefficient is an increasing function of the relative humidity.

\section{Acknowledgments}

None.

\section{Conflicts of interest}

The authors declare there is no conflict of interests.

\section{References}

1. Bledzki AK, Gassan J. Composites reinforced with cellulose based fibers. Progress in Polymer Science. 1999;24(2):221-274.

2. Rangaraj SV, Smith L. Effects of moisture on the durability of wood/ thermoplastic composite. Journal of Thermoplastic Composite Materials. 2000;13;140-61.

3. Dhakal HN, Zhang ZY, Richardson MOW. Effect of water absorption on the mechanical properties of hemp fiber reinforced unsaturated polyester composites. Composites Science and Technology. 2007;67(7-8):16741683 .

4. Le Duigou A, Davies P, Baley C. Seawater ageing of flax/poly (lactic acid) biocomposites. Polymer Degradation and Stability. 2009;94(7):1151-1162.

5. Hu RH, Sun MY, Lim JK. Moisture absorption, tensile strength and microstructure evolution of short jute fiber/polylactide composite in hygrothermal environment. Materials and Design. 2010;31(7):31673173 .
6. Assarar M, Scida D, El Mahi A, et al. Influence of water ageing on mechanical properties and damage events of two reinforced composite materials: Flax-fibres and glass-fibres. Materials and Design. 2011;32(2):788-795

7. Nabi Saheb D, Jog JP. Natural fiber polymer composites: a review. Advances in Polymer Technology. 1999;18(4):351-363.

8. Roudier A. Analyse multi-échelle du comportement hygro-mécanique des fibres de lin. École Doctorale Sciences pour l'Ingénieur de Clermont-Ferrand. Thèses. 2012.

9. Ntéppé-Nyame C. A new species for the genus rhektophyllum. Adansonia. 1981;20(4):451-457.

10. Béakou AR, Ntenga J, Lepetit JA, et al. Physico-chemical and microstructural characterization of "Rhectophyllum camerunense" plant fiber. Composites part A: applied science and manufacturing journal. 2008;39(1):67-74.

11. Betene EF. Study of the mechanical and thermal properties of plaster reinforced with tropical plant fibers. PhD thesis. Blaise Pascal University - Clermont-Ferrand II. 2012.

12. Noutegomo B, Betene E, Atangana A. Modelling moisture sorption isotherms of Rhecktophyllum camerunense vegetable fiber. European Journal of Pure and Applied Chemistry. 2017;4(1):2398-1385.

13. Pascal BOUSTINGORRY. Elaboration of a Gypsum Matrix Composite Material and Fragmented Wood Reinforcement - Improved resistance to screwing of prefabricated gypsum products. PhD thesis, National School of Mines of Saint Etienne and National Polytechnic Institute of Grenoble. 2002.

14. St John DA, Kelly JM. The flexural behavior fibrous plaster sheets. Cement and concrete research. 1975;5(4):347-362.

15. Singh Manjit, Verma CL, Garg Mridul, et al. Studies on sisal fibre reinforced gypsum binder for substitution of wood. Research and Industry. 1994;39:55-59.

16. Fick A. Ueber Diffusion. Annalen der Physik. 1855;170(1):59-86.

17. Crank J. The mathematics of diffusion. Clarendon Press, Oxford. 1975.

18. Célino AO, Gonçalves F, Jacquemin, et al. Qualitative and quantitative assessment of water sorption in natural fibres using ATR-FTIR spectroscopy. Carbohydr Polym. 2014;101:163-170.

19. Eyring H. Viscosity, Plasticity, and Diffusion as Examples of Absolute Reaction Rates. Journal of Chemical Physics. 1936;4(4):283-291. 